\title{
El cuerpo mochilero. Metáforas de la movilidad contemporánea
}

The backpacker body. Metaphors in the contemporary mobility

RESUMEN

Este ensayo de reflexión establece las bases del cuerpo viajero subsumido en una mochila, lo que da lugar a una nueva biocorporalidad: el cuerpo mochilero. Se establecen las bases de qué es el objeto mochila y cuál es su contexto de base en el andar y el hacer camino. El cuerpo mochilero se observa en la realidad de diferentes caminos: de orden material, desde la mochila en el Camino de Santiago (rutas de peregrinación cristiana de origen medieval por el Norte de España) hasta la que se da en el de las grandes gestas deportivas; pero también de orden ideacional, desde el cuerpo mochilero como aspiración del recorrido por el mundo en forma de orden capitalista, hasta la mochila como bagaje en el andar de la vida.

Palabras clave: mochila, camino, corporalidad, movilidad, viaje, poscapitalismo.

\section{ABSTRACT}

This work of reflection lays the foundations of the subsumed traveling body in a backpack, which gives rise to a new biocorporality: the backpacking body. We lay the foundation for what the backpack object is, and what is its basic context walking and making the way. Thinking about the backpacking body we observe it in the reality of different paths: firstly,
JosÉ-LUIS ANTA-FÉLEZ

Universidad de Jaén.

Área de Antropología

Social. Jaén, España.

\jlanta@ujaen.es

(1) ORCID: 0000-0001-7063-5288

ar Google Scholar 
in a material order, from the backpack on the way to Santiago to that given in the path of the great sports exploits; but also in the ideational order, from the backpacking body as aspiration of the journey through the world in the form of a capitalist order, to the backpack as a baggage in the walk of life.

Keywords: backpack, way, corporality, Mobility, trip, postcapitalism.

\title{
I. La mochila es una metáfora para la vida
}

\author{
"El que quiere llegar a cierta medida a la libertad de \\ la razón no tiene derecho, durante cierto tiempo, a \\ sentirse sobre la tierra otra cosa que un viajero [...] no \\ puede ligar fuertemente su corazón a nada particular: \\ es preciso que haya siempre en él algo del viajero que \\ encuentra su placer en el cambio y en el paisaje"
}

(Friedrich Nietzsche, 1880, El Anticristo)

$\mathrm{H}$ abitamos un mundo donde los sujetos han convertido todo en pura movilidad, donde los objetos, las personas y las ideas viajan saltando fronteras, cruzando umbrales y practicando la inquietud, pero a la vez, un mundo donde todo parece inamovible en el proceso del poscapitalismo, que se muestra como la única manera de movilidad posible, así como, la alternativa para no caer en un retroceso (Appadurai, 2006). En este mundo móvil la principal diferencia entre los sujetos y sus cosas es cómo viajan, cuáles son sus pertrechos y cómo atraviesan las fronteras, que cada vez más nos separan como productos ideológicos. El viaje, uno de esos productos desarrollados dentro de la idea de la movilidad poscapitalista - lo que sabemos es un régimen de movilidad-, se ha convertido en un ideal de vida y en una metáfora del propio mundo occidental, estableciendo capas, modelos y tipologías para todo gusto, sabor y forma de pensar (de manera general en el mobility turn y sus debates con el mundo global del transporte y los cuerpos viajeros (Glick-Schiller y Salazar, 2013; Hannam et al., 2006; Koslowski, 2011; Pujadas, 2012; Urry, 2007).

Como aquí veremos esta multiplicidad de viajes y viajeros, lejos de ser una posibilidad a la diversidad es, sobre todo, un engrandecimiento y amplificación de un discurso de disciplinamiento sobre los cuerpos para el consumo. Es más, lo importante no es si viajamos, sino cómo lo hacemos; 
si lo urgente no está en la reflexión del encuentro viajero, sino el constatar ante los pares que estuvimos allí; si lo razonable ya no es hacer el viaje que nos enfrente con nuestras ideas y valores, sino imponernos la idea de que los nuestros son los únicos posibles; si el viaje ya no es un descubrimiento, sino un constructo en que los otros son una anécdota. En este panorama, el viaje es, consecuentemente un elemento imprescindible de la fuerza de occidente, su modelo capitalista democrático y el nuevo espacio discursivo del colonialismo poshumanista.

En este sentido, digamos que hemos convertido el viaje en parte de una compleja red de categorías de desplazamientos. Por un lado, aquellas que tienen un sentido de ida y vuelta, frente a las que son un cambio de destino, y aquellas otras que implementan, con más o menos profusión, el ir cargados de objetos. Porque todo viaje impone un desplazar y llevarse cosas de nuestro mundo de origen, las más obvias, las de orden ideológico, las más evidentes, las de orden material -aquellas que nos unen con un mundo de pertenencias-. De ahí la maleta, la bolsa de viaje y, cómo no, la mochila. Viajar es desplazar física e ideológicamente un enorme y complejo sistema de objetos que de alguna manera tienen que ser contenidos. De hecho, no hay viaje sin mochila, maleta, macuto... hatillo. De la misma manera que todo bagaje, en la medida que responde a los objetos que creemos nos son imprescindibles para definirnos, es siempre el de lo vital. De ahí que, para el viaje contemporáneo, y aún más para el poscapitalista, el principal sistema de transporte de objetos sea la propia corporalidad y de ahí todo lo que supone transportar una y mil cosas.

¿Es el equipaje definitivamente aquello con lo que cargamos en nuestro viaje? Obviamente, de ahí que al final nos definamos por esto mismo. El equipaje, es decir, el conjunto de valores que nos acompañan en nuestro caminar, no es sino una serie de elementos que, construidos culturalmente, identificamos como nuestros tópicos o lugares comunes. El equipaje, más aún el bagage francés, es un lugar donde se hace presente la metáfora, donde las palabras se permiten el lujo de nombrar la cosa y lo que significan en otro contexto, haciendo que se confundan en última instancia los elementos dichos en función de un significado aparentemente común. De ahí que al final sea un objeto muy determinado, la mochila, como bagaje personal y corporalizado, el que termine por tomar la idea de lo que tenemos por equipaje vital. La mochila como una metáfora, de ahí en un feedback constante su mito como elemento personal y vital. Y del mito al rito de portar un mundo personal, sin mayores ataduras que las fuerzas del que lo lleva. Si la vida es un viaje, el equipaje que portamos es en cierta medida una mochila cargada de valores y tópicos, es decir, de los lugares por lo que hemos ido pasando. 
Pero, aun así, existe el viaje y el equipaje, de la misma manera que reconocemos al viajero y su sombra. Para el mundo contemporáneo todo viaje, ya sea metafórico o simplemente un mito asentado sobre un rito de constante peregrinar (a la playa o al trabajo, a la romería o a los viejos amores), no puede ser otra cosa que una movilidad de un cuerpo razonado, de un objeto en la medida que lo podemos observar fuera de nosotros (por ejemplo, en Cairncross, 1997 y Franquesa, 2011). La razón del viaje es la razón de su equipaje.

El viaje tiene como principal equipaje un elemento de fundir cuerpo y paisaje, haciendo lo que los estudiosos alemanes de la cognición -mi preferido sigue siendo Korbinian Brodmann- llaman "ser humano". En este sentido, qué es el cerebro sino un bagaje. El capitalismo avanzado convertirá esta razón humana en una razón utilitarista, llevando todo a su concepto de cuerpo para el consumo, ahora de viajes, ahora de elementos para el equipaje, incluso del móvil como exocerebro. Y reducido el cuerpo a su valor de consumo, frente a su valor de uso vital, todo lleva a que el viaje como desplazamiento corporal sólo sea un comportamiento, más que una experiencia. Quizás porque para el poscapitalismo, la forma concreta y contextual de la sociedad global del mundo actual, ya no hay viaje, sino itinerario, de la misma manera que ya no hay experiencia, sino palabras. En última instancia, una sociedad que ha hecho del control del riesgo y de la transparencia su razón de ser no puede concebir que viajar sea, ante todo, una experiencia donde lo que se pone a prueba es la vida (de manera muy genérica en la filosofía de Agamben, 2007; o la sociología de Beck, 1998). De hecho, la lírica romántica de Hölderlin (en Canto del destino de Hiperión, por ejemplo) nos enseñó que vivir es arriesgarse a encontrar la muerte en la siguiente esquina, roca y ola de lo incierto.

Esta experiencia de lo incierto es mucho de lo que aún se puede comprar en el viaje con mochila, el esfuerzo personal frente al camino, llevando de equipaje sólo lo más básico, sólo lo imprescindible para que podamos sentir que no somos uno más. Una suerte de individualidad extrema y concentrada en los cuerpos viajeros. Por qué ahora ya nadie habla con sus amigos de citoarquitectura, ya no sabemos susurrar que hemos leído el Mester de Clerecía y no podemos recordar que un día estuvimos a punto de partir a Tombuctú. Porque nada de esto cabe en una mochila, en el viaje extremo que requiere llevar lo imprescindible adherido al cuerpo sólo se puede soportar lo mínimo, el casi nada. A la última, como ya veremos un poco más abajo, en este viaje con mochila que nos venden en el mundo actual, y que hacemos como un principio de la búsqueda de algo llamado libertad, ya casi no cabe ni lo que nosotros mismos somos, mucho menos en lo que estamos o acaso hayamos estado. 
De hecho, las mochilas tampoco las tiene que llevar el propio sujeto de manera real, ni acaso ser responsables de ellas. Esto es lo bueno del viaje contemporáneo, la mochila como elemento dentro del consumo siempre es susceptible de renovarse, cederse o perderse. Porque lo importante es la razón utilitarista del viaje. El cuerpo mochilero es siempre robusto, es fuerte, en definitiva, está disciplinado. Sólo el mayor grado de disciplina permite saber que el itinerario puede ser otro. De hecho, gran parte de los nuevos viajeros con mochila tienen circuitos aparentemente más libres, más sufridos, menos trillados. Lo que sumado a lo imprescindible de lo transportado nos acerca a una nueva forma de ascetismo, donde parece que se revela la verdad de lo que el sujeto es. Pero, qué es. Obviamente sólo cuerpos en el consumo. Es incierto pensar, aunque eso parece llevar implícito el simulacro de viajar con una mochila, que el sujeto se acerca a lo místico, lo indecible, cuando sólo es un cuerpo que se consume. Claro que sólo es apariencia, el cuerpo mochilero no se consume, al contrario, se disciplina en la libertad contemporánea de elegir.

El capitalismo ve en la mochila un momento para unificar la idea de libertad, de relacionar aquellos conceptos que tienen que ver con el albedrío, con la posibilidad de ir donde el espíritu de los tiempos le lleve en la elección siempre racional, una vez más consciente y útil. Pero recordemos, la libertad en el capitalismo se llama deseo. Una compleja máquina deseante hace que los sujetos exploren una constante e infinita línea de adquisición de objetos que no pueden experimentar. Por eso, cuando vemos la mochila la clasificamos como un objeto infantil, a lo más juvenil, es decir como un elemento asociado a no tener proyecto, a no tener más que deseos. La mochila es ahora la metáfora de la libertad como deseo, ya no es una utopía, ya no es acaso un albedrío, es la democracia, es la política, es la unificación corporal en la libertad. Una mochila que es la representación contemporánea de la libertad, un objeto de deseo relativamente nuevo y que sirve de motor para la elección en el mundo del consumo. Y si el consumidor ejerce su libertad al adquirir esto o aquello, nos dicen los padres del mercado, que los que viajan con mochila son los más libres, pues su elección es siempre sobre lo necesario, sobre lo que siendo nada es imprescindible: el cepillo de dientes y la ropa interior, es decir, nuevos símbolos de esos cuerpos-soporte y, también, metáforas de su sanidad. 


\title{
II. El único camino posible es el que no tiene llegada
}

\author{
"Por nada su ligero paso acorta, aunque no sepa, pobre \\ peregrino, a donde ha de llevarle su camino.'
}

(Friedrich Nietzsche, 1883, Así hablo Zaratustra)

El lector in fabula que tengo en mente seguramente no ha viajado demasiado y mucho menos lo hace con una mochila, acaso con un pequeño hatillo, a lo más, una maleta de libros como Walter Benjamin. De la misma manera que el viajero con mochila es obviamente el que se puede ver en la plaza del Obradoiro de Santiago de Compostela, punto final del recorrido de las rutas conocidas como Camino de Santiago, viajes de peregrinación cristiana de origen medieval que hoy en día se hace de manera pedestre como parte de un ejercicio turístico-lúdico (véanse las etnografías de Acuña, 2000, 2015; Agís-Villaverde, 2008; PratCarós, 2011). La conjunción de ambos elementos no es sino la deformación de un pensamiento contra los cuerpos mochileros, por decirlo de alguna manera plástica; en última instancia son las ideas que nos animan a estar enfrentado al mundo que habitamos y conforma ese alrededor. De hecho, es parte de ver la mochila como un elemento característico de la acampada (una forma de colonialismo suave), la salida organizada a la civilizada naturaleza o, acaso, de las excursiones de fin de semana que hacían en el pasado los esforzados flechas y cadetes de la fascista OJE (Organización Juvenil Española, parecido a las juventudes hitlerianas a la manera española) y, en su defecto, de los complacientes Boys Scouts. El cuerpo mochilero es un objeto contemporáneo que plantea un enfrentamiento con lo establecido por el consumo de masas, para llevar la idea de viaje de lo turístico, como un cuerpo definido por la imposición, a un territorio de elección individual, de ahí la libertad y que no deja de ser un espacio de consumo tecnológico, retórico e ideológico dentro de una maquinaria deseante (ya estudiado por Martín-Cabello y GarcíaManso, 2015).

El Camino de Santiago es un espacio que se ha transformado profundamente en la contemporaneidad, hasta el punto de que se desprende de su ideal religioso medieval para convertirse en un punto característico de la individualidad, ideario consumista y planeador de los cuerpos como tecnología. Lejos de hacer el Camino como un espacio que termina con la recompensa en la llegada, la urgencia actual es sellar una cartilla que demuestra el itinerario seguido y que se convierte en un pasaporte muy sofisticado de la identidad y ocio de la cultura occidental. En este ambiente, la mochila es la reina de los equipajes, fuertemente unida a su 
binomio, el cuerpo, el nuevo rey de la creación. En el Camino la gente anda, se desplaza por el paisaje sufriendo la climatología, en cierta medida en un mundo donde lo normal es viajar en máquinas encapsuladoras, y en donde hacer el Camino tiene que ser lo más cercano a una experiencia de libertad. Y aunque no lo es, tiene tintes radicales de enfrentamiento con las estructuras políticas consensuadas, tal cual hacían los hobbos americanos en las líneas de tren de Chicago hacia el oeste o los carrileros, esos sujetos que recorren la geografía europea vagando de un lugar a otro.

Pero, por qué creer que el enfrentamiento con su esfuerzo y con el terreno que hacen los peregrinos es dentro de un marco de ocio, de reconocimiento de la meta y el Camino, en un itinerario con unas reglas, cuando menos, las del propio camino (estudiado para las romerías, verdaderos ejercicios de la movilidad ritualizada por Antón-Hurtado, 1996). Podemos acordarnos ahora, y valga de ejemplo, de la película The way (2010), de Emilio Estévez, donde a su atribulado y entristecido protagonista, un peregrino del Camino de Santiago, se le cae a un regato la mochila donde lleva las cenizas de su hijo, lo interesante es que pase lo que pase lo importante no es el contenido, ni acaso la mochila como tal, sino la regla de que el camino es una línea inquebrantable y que por medio de la mochila, una suerte de pasaporte de identidad, se puede dar una relación normativa con lo que allí se hace y cómo se hace. La mochila se convierte en una ficción, el soporte de un complejo nudo de relaciones entre los verbos caminar, transportar, encontrar y las formas ideológicas del pensamiento contemporáneo basadas en la idea del deseo. El resultado de todo ello es un performance llamado "cuerpo mochilero".

Desde aquí, lo que más interesante es observar la relación de la mochila, como un objeto privilegiado de esta forma de ocio que es el Camino de Santiago, donde el recorrido está alejado de la experiencia del andar - ese vagar de manera arbitraria y sin preparación en el encuentro con el paisaje-, pero a su vez, marca con mucha claridad la idea de que el capitalismo nos permite alguna forma de caminar, una actividad que mecaniza la corporalidad en función del concepto de movilidad (tema central de Gros, 2014 y Le Bretón, 2011). Es decir, habría que experimentar el andar y sin embargo lo que se hace en el Camino es recrear una tecnología del movimiento que reconocemos como el cuerpo mochilero. Es cierto, y no podemos cansarnos de repetirlo, que en el discurso del Camino hay mucho de las ideas que inspiran el andar, el encuentro con la naturaleza, el pensamiento propio y el extrañamiento, pero es quizás porque se trata de un viaje en forma de itinerario cerrado y mercantil, por lo que el proceso es de otro tipo. En este sentido la mochila quizás sea la clave, ya que al final es un lastre de una tecnología muy alejada de 
los problemas creados en el caminar, en el encuentro con el otro que hay dentro de cada paseante.

Lo que hace tan interesante a la mochila es, consecuentemente, que partimos de un objeto que tiende a ser parte de un discurso muy tecnológico, contemporáneo y capitalista. Al contrario que otras formas de transporte y equipaje -que aprovechan la idea de cargar por medio de unas correas, cinchas o arneses con los hombros-, o de tener la movilidad frontal que permite cargar algo a la espalda -como son los zurrones o bolsos de viaje en la espalda-, la mochila es un objeto de diseño que se significa en la medida que cumple una función alejada de los criterios de la estítica y donde la forma o los materiales empleados, así como su ideación y fabricación, centran el objeto. Como muchos de los objetos que vienen y van en esta idea moderna de la acampada, de lo montañero, de la agilidad, la funcionalidad y practicidad, se imponen a cualquier elemento de belleza, y no quiere decir que no respondan a una elegancia razonada, simplemente que no están dentro de los significantes de la estética. Quizás por ello son tan significativos los colores con los que se tintan las telas y materiales, y que responden a una visualización de la tecnología, no a una paleta poética del objeto.

Como herramienta, consecuentemente, pierde su posible mitificación en función de una constante acción ritual, la de ser acarreada. Obviamente no importa qué metamos en ella, eso es secundario; organizar una mochila es una tarea imposible, por eso quizás es un objeto que se tiene que pensar desde fuera, cuyo orden es una esquizofrenia, ya que remite a un mundo interior, ajeno a todo lo exterior, y cuya lógica es única y consecuentemente incomprensible.

Y de aquí arranca su diferencia radical con la maleta, hija del patético baúl viajero, la imposibilidad de esconder algo en su interior a futuro. La mochila como herramienta no permite que le guardemos en su interior cosas que quedaran olvidadas en el fondo del desván: ni mucho menos, es un objeto que dé identidad al que se desplaza por obligación, en última instancia la maleta define al emigrante, de la misma manera que la mochila no lo hace con su portador, con el que sólo cabe la idea de unificarse, de fundirse. Sería difícil imaginar, ni remotamente, a Juvenal Urbino, el coadyudante de El amor en los tiempos de cólera, guardando en el desván una mochila llena de los libros de la medicina romántica que encontraba en su afán de renovarse a los gustos de los nuevos tiempos afrancesados. La mochila es útil, no bella, es práctica, no poética. Como herramienta para el Camino, ahora el de Santiago, pero es seguro que en todos los caminos que lo han sido, responde a la practicidad de servir como 
elemento diferenciador a muchos niveles de la manera en quién, cómo y cuándo se recorre. Pero todo lo que diferencia es tan visible, tan público, que deja de ser importante. Nadie le da importancia a la mochila camino de Santiago, sino al esquizoide orden que mantiene con las cosas mínimas que nos sujetan a la supervivencia. Como se puede ver en todos esos peregrinos que contratan el servicio de alguna empresa que lleva su mochila hasta el siguiente hito -haciendo válida la fórmula de que el camino es hoy un nicho empresarial de primer orden-, para ser definitivamente cuerpos mochileros que ya sólo cargan con las urgencias de hacer el Camino sin mayor sufrimiento que el de su propio itinerario.

De hecho, hay toda una subjetividad sobre la mochila en el Camino, obviamente la queja de que pesa, de que se hace un objeto que siendo imprescindible termina por cansar y hacerse odioso, que nunca es lo suficientemente tecnológico y diseñado, y que tendría que estar a la altura del reto impuesto. Porque la mochila es parte del esfuerzo y, en cualquier caso, si no el esfuerzo mismo sí su más claro evocador, como tal, el símbolo perfecto del Camino como una tarea que impone una dinámica de cansancio y dolor. La mochila es desde estas subjetividades la carga definitiva, aquello que hace que el Camino sea largo y duro, esforzado y complejo, aquello que en cierta medida nos impone una realidad alejada del bucólico esfuerzo de pasear. El cuerpo mochilero crea subjetividades que plantean el dolor de recorrer el Camino, de dormir en las habitaciones compartidas, de los pies hinchados y doloridos, pero sobre todo de cargar con la mochila como una nueva forma de regocijo del cuerpo. Este cuerpo sufriente ya no es un cuerpo soporte, sino un cuerpo en el que el sufrimiento crea una dinámica de obligación en la felicidad. Cuerpos mochileros que sufren para ser felices, ahí radica la realidad de los seres poshumanos, de los sujetos de este capitalismo global.

La mochila, así, ya no es un objeto, un simple objeto, un bagaje, sino una identidad que define un cuerpo, el cuerpo mochilero, haciéndose un dispositivo que define la acción performativa que a modo de espejo da identidad a los sujetos. Pero la mochila, dispositivo disciplinador del poder del Camino empodera a los con ella se atreven, un empoderamiento que metamorfosea a sus usuarios a su imagen y semejanza. Podríamos decir que la mochila como dispositivo del Camino se acopla a cuerpo que es ergonómico a su funcionalidad. Obvio, como todos los objetos tecnológicos poscapitalistas es el cuerpo humano quien se acopla a ellos, frente a los objetos precapitalistas, claramente adaptados a un cuerpo que se consideraba inamovible, indeformable y funcional. Porque lo ergonómico no es adaptar el objeto al cuerpo humano, sino fundir el cuerpo en un objeto, haciéndose más eficiente el binomio para el trabajo, para la tarea, 
para el capital. La mochila, ya sujeta a ese cuerpo adaptado a su función, termina por modular el resto de la corporalidad en una ideología, una política de la movilidad.

\section{La mochila como lastre}

“¿Te dices libre? Quiero sentir tu pensamiento dominante y no que has huido de un yugo. [...] ¿Libre de qué? ¡Qué importa eso a Zaratustra! Tus ojos han de anunciarme con claridad: ¿libre para qué?"

(Friedrich Nietzsche, 1883, Así hablo Zaratustra)

Curiosamente el cuerpo mochilero que menos mochilas ha llevado en la historia contemporánea ha sido la figura de Tin Tin. Quizás porque su mochila física, real, sigue siendo montañera, excursionista, y aparece muy de vez en cuando; pero sin embargo con la que viaja es más verdadera, se trata de la de su coadyudante, su perro Milú y su alter ego, el capitán Haddock. Porque el cuerpo mochilero es un cuerpo tecnológico, una compleja red de dispositivos y relés que funcionan como una enorme creación del deseo. Podemos decir que la mochila es una tecnología del bagaje, del equipaje en su representación funcional, pero también de la corporalidad como maquinaria. Es por ello que lejos de las miradas contemporáneas planteadas por Tin Ha dock, la mochila actual es un enorme lastre que funcionaliza una sociedad, que hace de la movilidad, el traslado contante en la ausencia de experiencia. La mochila vital es inamovible de la corporalidad actual, porque la principal mochila no es la que se puede cargar, sino esa otra que hemos adherido a los sujetos: el cuerpo como carga vital.

La mochila se ha convertido en una mecánica para el transporte, y la encontramos en todos los sitios como elementos de la ideología funcional capitalista: las botellas de los buceadores y las mochilas para transportar a los conquistadores del siglo XVII, que tan bien retratara Guamán Poma de Ayala, o las culturas que llevan a los niños a la espalda, o el Asia industrial donde ejércitos de hombres llevan cargas imposibles de aquí para allá, pero también las cargas de esos negros de las películas de Tarzán o el traficante de indios Rodrigo Mendoza, que interpreta Robert de Niro, de la Misión, que lleva sus pertrechos de conquistador a la espalda, como metáfora de la vida de pecado que desea expiar o las mochilas llenas de explosivos, con las que la prensa occidental asocia a los nuevos terroristas globales, y que son el símbolo perfecto de la movilidad e impunidad de los 
nuevos ejes del mal. Y, por encima de todo, esas mochilas de hoy que usa el ejército y que se ven recreadas en el desarrollo de los exoesqueletos. En efecto, la mochila es una práctica de transporte en la disciplina, y también un objeto para conformar las ideas de las clases sociales, de las fronteras y sus símbolos (centrado en el doble paradigma de la movilidad y las formas de transportarse véase Gaggiotti, 2011; Shamir, 2005; Salazar, 2011). Así es, frente al cuerpo mochilero del viajero del Camino de Santiago, de los jóvenes norteamericanos recorriendo Chile con sus Backpacks (descrito en Martín-Cabello, 2014), está el cuerpo colonial y el cuerpo disciplinado, lastres de un mundo muy alejado de la libertad.

La tecnología corporal de la mochila, la del cuerpo mochilero por antonomasia de esos jóvenes que recorren el mundo en su idea de viajes en independencia, aunque no en libertad, es sustituido hoy en las miradas capitalistas, por la del militar que con su macuto a la espalda vive recorriendo el mundo en busca permanente de espacios en los que imponer su paz. Este nuevo, y a la vez tradicional, cuerpo mochilero-militar, que vaga sobre su mochila o regresa en ella, es un sujeto disciplinado en la idea de las tecnologías del cuerpo como dispositivo. Tiene, además su correlato en el mundo civil en esos esforzados niños de todo el planeta que llevan sus mochilas por las calles desde sus hogares a sus colegios, lo que les convierte en disciplinados cuerpos del bagaje cultural, que a falta de otra ideología de control es la forma más atroz de esclavismo en que vive la humanidad desde que fuera creada en el siglo XVIII, ya que no sólo les obligamos a socializarse en nuestra lengua, con nuestros dioses y en nuestras costumbres, sino que les exigimos llevarlas a cuestas hasta el momento en que creemos afirmativamente que sus cuerpos se han deformado y plegado a la mochila que durante tanto tiempo les ha servido como horma.

Estos cuerpos mochileros, que sirven a un ideal disciplinario, a la vez que a un grupo que plantea una cierta idea de libertad, se ven restringidos, a su vez, por un contexto que impone que la mochila es un limitante social, no sólo porque niega la idea del viaje como un lujo, sino porque no permite el viaje como abandono. De hecho, recrean una idea del camino en función de una terapéutica (Comelles, 1984). De ahí, primero, que el cuerpo mochilero no sea un sujeto que experimente el paseo, ya que la mochila le limita en cuanto que le transforma. Y, segundo, la mochila en su funcionalidad restringe la poética de llevar más equipaje que el realmente necesario. El cuerpo mochilero, en su limitación funcional, sólo puede consecuentemente seguir el itinerario marcado para su actividad; de hecho, el mochilero, en cuanto cuerpo viajante, no conectará nunca con los nativos por donde pasa, acaso con algún anfitrión que le abra 
ligeramente las puertas de un pintoresco rincón creado ex proceso para él y su mochila.

Pero esta disciplina de la mochila crea un corpus, ya vimos que por un lado de carácter biologista, al imponer una adaptación del cuerpo al objeto, transformándolo en su forma y contenido, resignificándose como un cuerpo en uso, por otro, es una transformación ideológica, y por último impone una política. Este corpus político que al final significa y recrea al sujeto en un cuerpo mochilero, primero, porque atañe a la disciplina del itinerario, con las implacables leyes asociadas al régimen de movilidad, $\mathrm{y}$, segundo, lo hace por medio de una razón jurídica que impone la idea de un desarrollo permanente, así como avanzar como única posibilidad. Al final si la mochila es un dispositivo, sólo puede funcionar dentro de dispositivos mayores, una mochila está hecha para ser cargada en el dispositivo del viaje mochilero, del viaje en el encuentro con la ideología capitalista multimercado. En última instancia es ingenuo creer que por que se viaja con una mochila se es menos consumista, o más libre, que el que lo hace con la familia cargando su coche con sombrillas de playa y neveras portátil para la cerveza. La razón disciplinaria del cuerpo mochilero no reside en que se puede hacer lo que se quiera siempre que sea, dentro de la lógica del itinerario (capitalista) mochilero.

Además, el cuerpo mochilero es público, es de todos los viajes el más visible, el más controlable y el más anunciado. De hecho, está expresamente hecho para que sea vea: al viajar con la mochila a cuestas, o en su defecto con un cuerpo abducido por la una mochila, formando un único objeto subjetivizante, sólo puede ser entendido en su propia definición, y la mochila imprime el carácter que denota el estar imbuido del discurso del capitalismo que consume espacio, pero que lo hace como parte del propio espectáculo que crea. El cuerpo mochilero es en el corpus político un objeto performativo, es actor del atrezo que él mismo crea. Su mochila configura un tipo de viaje que transforma el camino para ser recorrido sólo, exclusivamente con mochila. Hoy en día no es fácil de ver porque gran parte de los viajes mochileros se hacen por sujetos que no se les ve la mochila como un objeto exento, y no porque no la tengan, sino porque son claramente una única cosa. Pero si observamos el origen de algunos célebres cuerpos mochileros, como aquellos que recorren las cumbres más altas del planeta, su itinerario, pongamos que las rutas para subir a las cumbres del K2 o el Everest, están marcados por la capacidad de la mochila, la que termina por establecer cuál es el camino y las posibilidades de este, en un juego simbiótico, pero también homeostático, entre el camino como constructo de posibilidad y el camino como realidad única con la mochila. Pero no es simplemente una performatividad de 
unificación de corporalidades e itinerarios, es una biopolítica. En cierta medida porque ni todo el mundo puede transformarse en cuerpo mochilero, ni se le permite cualquier cosa a los que cumplen con el cliché. Y son este grupo de normas las que hacen que el cuerpo rebaje sus valores de libertad y agilidad en función de un discurso de la movilidad total.

Nos quedaría hablar, por último, de la mochila como un elemento que sirve, también, de soporte identitario de algún sistema sexo-genérico. Aunque más bien de cómo es el conformador de cuerpos transformados en ideologías de géneros. Sin embargo, el discurso de los cuerpos mochileros se centra en establecer, en su versión adulta y clasista, siempre heteronormativa y patriarcal, la misma idea con el objeto de la caravana, el camping o la roulotte que, con la casa a cuestas, establecen el criterio de la movilidad absoluta y la no sujeción a nada porque nadan necesitan. En cierta medida es un discurso que el capitalismo ya había utilizado en diferentes versiones, durante la etapa del colonialismo, momento clave para observar la creación de las políticas viajeras, y, sobre todo, en lo que ocurre en ciertas partes del mundo como un sobre-desarrollo. En efecto, en la Europa central, algunas partes del Estados Unidos y Canadá, el capitalismo avanzado había establecido que llegado un momento dado se podía permitir que los individuos, favorecido por el enorme desarrollo de la individualidad y el absoluto control del riesgo, pudiesen llegar a vidas, digamos, de bajo consumo, pero de gran impacto consumista, ya que el gasto del Estado es tan exagerado que se pueden permitir el lujo de ciudadanos que tuviesen poco, cambiando calidad por cantidad. En este contexto la mochila es una suerte de metáfora religiosa de los mínimos, un ascetismo, sobriedad y mesura en el bagaje. La mochila como una suerte de transformación de la cruz cristiana, un símbolo análogo de la liberación carnal por el sufrimiento. Una religión en que la creencia es que la libertad se consigue en función de que se carga con lo imprescindible y en la aplicación de que en el itinerario está todo. Y si la mochila servía de metáfora de lo que cargamos en nuestras vidas -como el objeto que nos permite recoger aquellos valores, ideas y sentimientos que nos definirán el resto de nuestros días-, la mochila/cruz del cuerpo mochilero es aquella que establece una política de los mínimos para poder construir la movilidad en y para sujetos con una exagerada individualidad poscapitalista.

En este sentido la metanarrativa del cuerpo mochilero no plantea tanto un ejercicio de libertad, aunque sea una parte del discurso, sino del enfrentamiento con uno mismo, una subjetividad que expresa el mundo como si los sujetos se extraviasen en la realidad urbana actual y pudiesen, por medio de la iniciación ritual de acarrear una mochila, el encontrar lo que creen que son. En novelas como Terapia, de David Lodge, o Bueno me 
largo, de Hape Kerkeling (estas hacen referencia al Camino de Santiago, aunque seguro encontraremos otras en otros itinerarios mochileros), se habla de un proceso de transformación personal en función del caminar, una suerte de moderna ritualidad que permite, por medio de los viejos valores del esfuerzo, el dolor y el ascetismo recuperar parte de lo perdido en lo mundos contemporáneos. Así el Camino se convierte en este sentido, por ser el reverso negativo de los mundos urbanos poscapitalistas, en un espacio terapéutico. Pasa con otros itinerarios, como El Rocío, esa otra gran fiesta de la identidad consumista andaluza, no tan global como el Camino, pero igualmente significativa del ritual del capitalismo individual (Martínez-Moreno, 1997). En todos estos itinerarios los sujetos se convierten en unos otros que les sirven de modelo de existencias que no les corresponden, un simulacro de vida, que se entiende como un potente y significativo transformador de la subjetividad, pero que no pasa de ser un espejismo del desarrollo capitalista que impone la individualidad como único espacio del destino social. Nadie duda de la transformación personal en el Camino, aunque su validez es nula, simplemente porque el viaje no se hace como transformador de los sueños sociales globales y, consecuentemente, el retorno es siempre a un contexto donde el mercado impone que se puede o no sentir, un retorno a la fuente de la insatisfacción, el capitalismo como máquina deseante que permite la cura en el Camino, pero no el retorno a la sanidad social.

Y en esto hay una coincidencia histórica: la democracia neoliberal y el capitalismo nacieron para controlar el exceso de gobierno, el sobregobierno característico de la sociedad jacobina, de la misma manera que los cuerpos mochileros son una suerte de valor biopolítico. Sobre el cuerpo se aplica un objeto que funde la idea de que ya nada vale sino puede ser cargado por cada sujeto, haciendo coincidir en un único punto existencia, deseo y destino. Seguramente los cuerpos mochileros conforman una nueva y revisada forma de ver el mundo por los grupos hegemónicos occidentales, una profundización de aquella forma de nueva religión totalitaria que había reconocido Benjamín en el capitalismo. Pero hay algo que no podemos olvidar, que sólo en el andar se hace pensamiento, el encuentro del sujeto crítico con la subjetividad y con la experiencia, y que a su vez todas ellas se desarrollan en el paseo pausado, en el reconocimiento de la senda y en la mirada lejana sobre el paisaje natural. Seguramente han sido Rimbaud, Thoreau, Machado o Solnit, los pensadores y poetas de la modernidad contemporáneas, los que nos han enseñado que al andar encontramos los trozos de nosotros mismos, en forma de piedras y memoria y que sirven como resistencia, nostálgica a un mundo de acelerado movimiento; por eso los mochileros nos siguen pareciendo una simpática figura del mundo viajero: se tornan por un momento en lentos 
soñadores. Pero si este amable cuerpo mochilero conforma un equipaje de valores y experiencias, de idas y clichés, de corpus y normas habría que apostar, por lo contrario, por la disidencia que diría Nietzsche -acaso Artaud-: viajar ligero de equipaje para olvidarse de todo, hacer del paseo algo inútil, improductivo, estéril, que sólo y exclusivamente sirva para vivir, sintiendo la inevitable confusión del lento devenir del pensamiento y el paisaje.

\section{Coda}

El mito de la sociedad poscapitalista nos dice que si de verdad viajáramos tendríamos que tomar conciencia de que el riesgo es el cambio; no adquirir una nueva idea, y acaso el reforzar un valor o ver cómo toma importancia un paisaje o el tiempo, pero nada de eso. El riesgo del viaje es que ya no seamos el que lo emprendió. Este viaje de transformación del interior vería que lo de fuera es lo más interesante y que lo importante es externo a nosotros y, en consecuencia, que lo urgente es la transformación de nuestros anclados interiores. Por eso, el viaje más atroz es el interior, el viaje por ese paisaje de la vida propia, donde lo lógico es pensar que tenemos que perder todo rastro de identidad. Viajar para cambiar. Y volver a viajar. Un cambio constante. Una dinámica del perpetuo rito de cambiar constantemente. Hasta el punto de que sólo exista el viaje y los sujetos ya no puedan reconocerse, haciendo del anonimato absoluto el único valor de la vida. Una vida en sociedad, compartida en múltiples sujetos viajeros, en constante transformación, una vida que ve como lo que sabemos de los demás se difumina en el nuevo cambio operado en el viaje. Nada sabríamos con certeza, nada podríamos ver para siempre, no podríamos juzgar ni tener normas, no habría cuerpos físicos ni almas inmortales, ya que todo lo que sabemos se disolvería en el viaje. Por eso para que este no fuese un riesgo que terminase con nuestra cultura, los dioses nos pusieron una mochila, para que cargásemos en las espaldas todo lo que somos y no podemos transformar, todo lo que deseamos y que logramos. Para que, la llevemos encima y nos defina frente al anonimato. El precio que hemos pagado por esa mochila es no poder cambiar nunca más. 


\section{Referencias bibliográficas}

Acuña, A. (2000). Cuerpo sufrido, cuerpo disfrutado en el Camino del Rocío. Aestuaria. Revista de investigación, (7), 65-90.

Acuña, A. (2015). El camino y lo sagrado en las rutas gallegas a Santiago. Revista Nuevas Tendencias en Antropología, (6), 21-49. http://www.revistadeantropologia.es/Textos/ N6/El\%20camino\%20y\%20lo\%20sagrado.pdf

Agís-Villaverde, M. (2008). Antropología de la peregrinación. ¿Quiénes son los peregrinos? XI Encuentro de Santuarios de España. Santiago de Compostela: Conferencia Episcopal Española. http://www.conferenciaepiscopal.nom.es/pastoral/turismo/encuentro/ $\mathrm{xi} /$ marcelinoagis.pdf

Agamben, G. (2007). Infancia e Historia. Buenos Aires: Adriana Hidalgo Editora.

Antón-Hurtado, F.(1996). La romería de Murcia en Espagne. Un pèlegrinage entre changement et continuité. Revue des Sciences Sociales de la France de l'Est, 23, 104-109.

Appadurai, A. (2006). Cosmopolitan Vision. Polity Press.

Beck, U. (1998). La sociedad del riesgo. Hacia una nueva modernidad. Paidós.

Cairncross, F. (1997). The Death of Distance: How the Communications Revolution will Change our Lives. Harvard Business School Press.

Comelles, J. M. (1984). Los caminos del Rocío. En S. Rodríguez-Becerra (ed.), Antropología cultural de Andalucía (pp. 425-445). Consejería de Cultura de la Junta de Andalucía.

Franquesa, J. (2011). "We've lost our bearings": place, tourism, and the limits of the "mobility turn". Antipode, 43(4), 1012-1033. https://doi.org/10.1111/j.1467-8330.2010.00789

Gaggiotti, H. (2011). Narrating expatriation and making sense of the globalization experience. En E. Bonet, B. Czarniawska, D. McCloskey y H. Jensen (eds.), Rhetoric and Narratives in Management Research (pp. 293-306). ESADE Business School.

Glick-Schiller, N. y Salazar, N. (2013). Regimes of mobility across the globe. Journal of Ethnic and Migration Studies, 39(2), 183-200. https://doi.org/10.1080/1369183X.2013.723253

Gros, F. (2014). Andar, una filosofía. Taurus.

Hannam, K., Sheller, M. y Urry, J. (2006). Editorial: Mobilities, Immobilities and Moorings. Mobilities, 1(1), 1-22. https://doi.org/10.1080/17450100500489189

Koslowski, R. (2011). Global Mobility Regimes. Palgrave-Macmillan. https://doi.org/10.1057/ 9781137001948

Le Bretón, D. (2011). Caminar: un elogio. Siruela.

Martín-Cabello, A. (2014). El turismo "backpacker" en Chile como expresión de una subcultura juvenil. Cuadernos de turismo, (34), 165-188. https://doi.org/10.13140/2.1.3763.7768

Martín-Cabello, A. y García Manso, A. (2015). Una aproximación a las relaciones entre el turismo mochilero y la cultura corporativa global. Antropología experimental, (15), 55-72. https://doi.org/10.17561/rae.v0i15.2365

Martínez Moreno, R. M. (1997). La romería del Rocío en Andalucía, una fiesta de la posmodernidad. Gazeta de Antropología, (13). https://doi.org/10.30827/Digibug.13566

Pujadas, J. J. (2012). Itinerarios metropolitanos: policentrismo, movilidad y trayectorias personales en la ciudad porosa. Biblio 3W: Revista bibliográfica de geografía y ciencias sociales, XVII(968). http://www.ub.es/geocrit/b3w-968.htm 
Prat-Carós, J. (2011). ¿Por qué caminan? Una mirada antropológica sobre el Camino de Santiago. En A. M. Nogués y F. Checa (coords.), La cultura sentida. Homenaje al profesor Salvador Rodríguez Becerra (pp. 495-529). Signatura Demos.

Salazar, N. (2011). Grounding mobilities: Rethinking border-crossing tourism and migration. En E. Judd y J. Zhang (comps.), Labour Migration and Social Mobility in Asia and Pacific Region (pp. 8-25). Intellectual Property Publishing House.

Shamir, R. (2005). Without Borders? Notes on Globalization as a Mobility Regime. Sociological Theory, 23(2), 197-217. https://doi.org/10.1111/j.0735-2751.2005.00250.x

Urry, J. (2007). Mobilities. Polity Press. 